\title{
Diabetic retinopathy in people aged 70 years or older. The Oulu Eye Study
}

Department of Ophthalmology, University of Oulu, Oulu, Finland H Hirvelä

L Laatikainen ${ }^{\star}$

^Present address:

Department of

Ophthalmology,

University of Helsinki,

Helsinki, Finland.

Correspondence to: Heli Hirvelä, MD,

Department of

Ophthalmology, University

of Oulu, 90220 Oulu,

Finland.

Accepted for publication 8 October 1996

\begin{abstract}
Aims-To evaluate the presence and severity of diabetic retinopathy and the value of retinopathy screening in people aged 70 years or older.

Methods-In a population based study on 500 of 560 eligible (89\%) people aged 70 years or older, signs of diabetic retinopathy were evaluated through dilated pupils by an ophthalmologist using photographic and/or ophthalmoscopic methods.

Results-23\% of the study population (113/500) had diabetes mellitus. Signs of diabetic retinopathy were found in 24 people ( $21 \%$ of the diabetic population). Retinopathy changes were graded as mild to moderate non-proliferative retinopathy (NPDR) in 40 eyes (18 people), severe NPDR (preproliferative) in five eyes (four people), and proliferative in three eyes (two people). Preproliferative or proliferative changes were present in four people $(3.5 \%$ of the diabetic population) and diabetic maculopathy was diagnosed in nine $(8 \%$ of the diabetic population). Laser treatment was considered to be indicated in seven people for maculopathy, and in two for proliferative changes. In four people the visual acuity was reduced to a low vision level as a result of diabetic retinopathy.

Conclusion-In spite of the high prevalence of diabetes mellitus in the elderly population, the prevalence of vision threatening diabetic retinopathy, particularly proliferative retinopathy, is low. Ophthalmoscopically, reliable information on fundus changes could be obtained in $94 \%$, but photographs were gradable in only $76 \%$ of the diabetic population. Therefore, the value of photographic screening for diabetic retinopathy in this age group is poor in comparison with younger age groups.

(Br f Ophthalmol 1997;81:214-217)
\end{abstract}

Diabetic retinopathy is one of the major causes of blindness in developed countries. Patients with insulin dependent diabetes mellitus (IDDM) have a higher risk of developing severe proliferative diabetic retinopathy (PDR) than those with non-insulin dependent diabetes mellitus (NIDDM). However, a greater number of cases of severe PDR are related to NIDDM, because its prevalence in the general population is much higher. ${ }^{1}$ NIDDM accounts for $90 \%$ of diagnosed cases of diabetes. ${ }^{2}$

Knowledge on the epidemiology of diabetic retinopathy among the elderly is scanty. Most studies include only those aged $30-70$ years or selected cases. Studies using, for example, clinic populations or only non-institutionalised populations, although revealing much important data, may suffer from selection bias and therefore do not give a true picture of the overall burden of disease carried by old people.

The prevalence of diabetic retinopathy and its correlates in the elderly population are important to know, because the number of old people is constantly increasing. To detect even the lowest grade of retinopathy, fundus photography has been recommended as the screening method instead of ophthalmoscopy. However, when examining elderly people cataract may compromise the effort.

Our aim was to examine the prevalence and severity of diabetic retinopathy in the entire population aged 70 years or older in three rural communities in Finland in order to decide whether photographic screening for retinopathy is indicated in this age group.

\section{Patients and methods}

In a population based study on 500 of 560 eligible $(89 \%)$ inhabitants aged 70 years or older of three communities in the county of Oulu, Finland, diabetes mellitus was diagnosed in 113 people $(23 \%)$. Of these, 52 (46\% of the diabetic population) had either peroral (34) or insulin medication (seven) or both (11). The study population and the non-participants have been described in detail in previous reports. ${ }^{34}$

The fasting blood glucose level of all participants was measured in the morning between 8 and 10 o'clock. In subjects not taking antidiabetic medication a glucose tolerance test using $75 \mathrm{~g}$ of glucose in $300 \mathrm{ml}$ was performed. The diagnosis of diabetes was based on use of hypoglycaemic medication or high random fasting blood glucose level $(\geq 7.0 \mathrm{mmol} / \mathrm{l})$ or high glucose level observed in the glucose tolerance test ( $\geq 11.0 \mathrm{mmol} / 1$ at 2 hours $)$ at the time of the examination.

Hypertension was defined as the use of antihypertensive medication, or a systolic blood pressure $\geq 160 \mathrm{~mm} \mathrm{Hg}$, or diastolic blood pressure $\geq 95 \mathrm{~mm} \mathrm{Hg}$.

All people were initially examined with direct ophthalmoscopy or biomicroscopy with the $90 \mathrm{D}$ Volk lens or/and the Goldmann three mirror lens. After that, non-stereoscopic $45^{\circ}$ 
Table 1 Distribution of diabetes mellitus and diabetic retinopathy in study population by age

\begin{tabular}{llc}
\hline & \multicolumn{2}{l}{ Number of people } \\
\cline { 2 - 3 } Age group (years) & Diabetes mellitus & Retinopathy \\
\hline $70-74(\mathrm{n}=197)$ & 43 & 11 \\
$75-79(\mathrm{n}=139)$ & 35 & 5 \\
$80-84(\mathrm{n}=105)$ & 30 & 8 \\
$85-89(\mathrm{n}=42)$ & 5 & 0 \\
$\geq 90(\mathrm{n}=17)$ & 0 & 0 \\
\hline
\end{tabular}

Table 2 Frequency distribution of the various signs of diabetic retinopathy

\begin{tabular}{|c|c|c|}
\hline Sign & $\begin{array}{l}\text { Number of } \\
\text { eyes }(n=48)\end{array}$ & $\begin{array}{l}\% \text { of eyes with } \\
\text { retinopathy }\end{array}$ \\
\hline \multicolumn{3}{|l|}{ Microaneurysms } \\
\hline$\leq 10$ & 29 & 60 \\
\hline$>10$ & 17 & 35 \\
\hline Haemorrhages & 30 & 63 \\
\hline Macular oedema & 13 & 27 \\
\hline \multicolumn{3}{|l|}{ Hard exudates } \\
\hline in macula & 7 & 15 \\
\hline outside macula only & 10 & 21 \\
\hline Microinfarcts & 7 & 15 \\
\hline \multicolumn{3}{|l|}{ New vessels } \\
\hline on the disc & - & - \\
\hline on the retina & 2 & 4 \\
\hline both & 1 & 2 \\
\hline Fibrous proliferation & 2 & 4 \\
\hline \multicolumn{3}{|l|}{ Preretinal or vitreous } \\
\hline haemorrhage & - & - \\
\hline Retinal detachment & - & - \\
\hline
\end{tabular}

photographs on both eyes using the nonmydriatic camera (Canon NM CR4-45NM) with a green filter (Wratten No 58) and black and white Kodak Panatomic-X film were taken whenever the individual cooperated and was able to sit and the media were clear. For both examinations the pupils were dilated with $0.5 \%$ tropicamide and $10 \%$ phenylephrine. The diagnosis of diabetic retinopathy was based on fundus photography in 95 of the 113 diabetic patients and on careful ophthalmoscopy in 15. In three diabetic patients the fundus could not be seen because of lack of cooperation (one patient) or dense cataract (two patients). For grading of the fundus changes enlarged paper prints $(13 \times 18 \mathrm{~cm})$ were used.

The photographs were first graded by one of the authors and later on the questionable lesions were discussed and adjudicated by the two authors together. The graders were blinded as to the status of the glucose metabolism of the participants. The classification of diabetic retinopathy was performed using a modified scale of the Early Treatment Diabetic Retinopathy Study. ${ }^{5}$ The eye with the most severe retinopathy determined the severity of retinopathy in a person.

\section{DATA ANALYSIS}

The categorised data variables were described by the frequency distribution. The $\chi^{2}$ test, corrected for continuity when appropriate, was used to evaluate the significance of the differences between categorised data.

\section{Results}

Signs of diabetic retinopathy were found in 24 people $(21 \%$ of the diabetic population and $5 \%$ of the whole study population); $21 \%(7 / 34)$ of diabetic men and $22 \%(17 / 79)$ of diabetic women had retinopathy $(\mathrm{p}=0.9)$. The distribution of diabetes mellitus and diabetic retinopathy by age is presented in Table 1 .

Gradable fundus photographs were obtained in 95 diabetic patients, in 15 only ophthalmoscopic findings were available. In 22 the diagnosis of retinopathy was based on photography, in two on ophthalmoscopy. The most common findings in these 48 eyes were microaneurysms (in 46 eyes, 96\%) and haemorrhages (in 30 eyes, 63\%) (Table 2). Hard exudates in the macula and/or outside the macular area were found in 17 eyes (35\%), cotton wool spots in seven eyes $(15 \%)$, and new vessels were found in three eyes $(6 \%)$.

The severity of retinopathy was graded as mild to moderate non-proliferative retinopathy (NPDR) in 40 eyes (18 cases), severe NPDR (preproliferative) in five eyes (four cases) and proliferative in three eyes (two cases) (Tables 3 and 4). Preproliferative or proliferative changes were present in four cases $(3.5 \%$ of the diabetic population).

There were no cases of vitreous haemorrhage or retinal detachment related to diabetic retinopathy. Diabetic maculopathy was diagnosed in 13 eyes of nine diabetic patients $(8 \%$ of the diabetic population).

Laser treatment had earlier been performed in four eyes of three people. In three eyes the treatment had been done for both macular and peripheral changes, in one eye only peripheral changes had been treated. Indications for new

Table 3 Severity of diabetic retinopathy for individual eyes in the study population according to Early Treatment Diabetic Retinopathy Study Scale (Diabetes Control and Complications Trial $5^{5}$ )

\begin{tabular}{|c|c|c|c|c|}
\hline Level & Severity* & Definition * & $\begin{array}{l}\text { Right eyes } \\
(n)\end{array}$ & $\begin{array}{l}\text { Left eyes } \\
(n)\end{array}$ \\
\hline 10 & No retinopathy & Diabetic retinopathy absent & 84 & 84 \\
\hline 20 & Very mild NPDR & Microaneurysms only/1 haemorrhage & 11 & 12 \\
\hline 35 & Mild NPDR & Microaneurysms plus hard exudates, cotton wool spots, and/or mild retinal haemorrhages & 9 & 6 \\
\hline 43 & Moderate NPDR & Microaneurysms plus mild IRMA or moderate retinal haemorrhages & 0 & 2 \\
\hline 47 & Moderate NPDR & More extensive IRMA, severe retinal haemorrhages, or venous beading in one quadrant only & 1 & 0 \\
\hline 53 & Severe NPDR & $\begin{array}{l}\text { Severe retinal haemorrhages in four quadrants, or venous beading in at least two quadrants, or moderately } \\
\text { severe IRMA in at least one quadrant }\end{array}$ & 1 & 3 \\
\hline 61 & Mild PDR & NVE $<0.5$ disc area in one or more quadrants & 1 & 1 \\
\hline 65 & Moderate PDR & NVE $\geq 0.5$ disc area in one or more quadrants or NVD $<0.25-0.33$ disc area & 0 & 0 \\
\hline $71-75$ & High risk PDR & NVD $\geq 0.25-0.33$ disc area and/or vitreous haemorrhage & 1 & 0 \\
\hline $81-85$ & $\begin{array}{l}\text { Advanced PDR, } \\
\text { fundus partially } \\
\text { obscured }\end{array}$ & & 0 & 0 \\
\hline
\end{tabular}

${ }^{\star}$ Diabetes Control and Complications Trial definitions.

NPDR = non-proliferative diabetic retinopathy; IRMA = intraretinal microvascular abnormalities; PDR = proliferative diabetic retinopathy; NVE = new vessels elsewhere; NVD = new vessels on or within 1 disc diameter of optic disc. 
Table 4 Severity of diabetic retinopathy for people in the study population according to Early Treatment Diabetic Retinopathy Study Scale (Diabetes Control and Complications Trial ${ }^{5}$ )

\begin{tabular}{llll}
\hline Step & $\begin{array}{l}\text { Level } \\
\text { (worse eye/better eye) }\end{array}$ & $\begin{array}{l}\text { Number of } \\
\text { people }\end{array}$ & $\begin{array}{l}\text { \% of diabetic } \\
\text { people }(n=113)\end{array}$ \\
\hline 1 & $10 / 10$ & 86 & 76 \\
2 & $20 /<20$ & 1 & 1 \\
3 & $20 / 20$ & 10 & 9 \\
4 & $35 /<35$ & 2 & 2 \\
5 & $35 / 35$ & 6 & 5 \\
6 & $43 /<43$ & 1 & 1 \\
7 & $43 / 43$ & 0 & 0 \\
8 & $47 /<47$ & 0 & 0 \\
9 & $47 / 47$ & 0 & 0 \\
10 & $53 /<53$ & 2 & 2 \\
11 & $53 / 53$ & 0 & 0 \\
12 & $\geq 61 /<61$ & 2 & 2 \\
Not known \\
(non-cooperative/dense
\end{tabular}

laser treatment were found in seven eyes of four people for macular exudates, in six eyes of three people for macular oedema related to preproliferative retinopathy, and in three eyes of two people for proliferative changes. Thus, in nine people ( $2 \%$ of the study population or $8 \%$ of the 113 diabetic cases) laser treatment was indicated.

Retinopathy was more common in patients on insulin treatment $(61 \%)$ compared with those taking tablets (18\%) (Table 5). Three people with newly diagnosed diabetes had retinopathy changes (mild background retinopathy). The prevalence of diabetic retinopathy was less than $10 \%$ in people who had had diabetes mellitus for less than 10 years, but after 10 years' duration the prevalence increased (Table 6). Hypertension was more prevalent and blood pressure was higher in subjects with retinopathy compared with those without; $83 \%(20 / 24)$ of those having diabetic retinopathy had antihypertensive medication, while in the rest of population the rate was $54 \%(p=0.005)$.

In four people ( $7 \%$ of all the visually handicapped people in this age group) the main cause of low vision (visual acuity less than 0.3

Table 5 Prevalence of diabetic retinopathy by type of treatment of diabetes mellitus

\begin{tabular}{llll}
\hline & \multicolumn{3}{l}{ Retinopathy (no of people) } \\
\cline { 2 - 4 } Treatment & Yes & No & Not known \\
\hline Diet & 4 & 20 & 1 \\
Diet + tablets & 6 & 27 & 1 \\
Diet + tablets + insulin & 7 & 4 & 0 \\
Diet + insulin & 4 & 2 & 1 \\
No treatment (newly diagnosed & & 33 & 0 \\
$\quad$ DM) & 3 & 33 & \\
\hline
\end{tabular}

Table 6 Prevalence of diabetic retinopathy by duration of diabetes mellitus

\begin{tabular}{llcc}
\hline \multirow{2}{*}{ Duration of diabetes (years) } & \multicolumn{3}{l}{ Retinopathy (no of people) } \\
\cline { 2 - 4 } & Yes & No & $\%$ \\
\hline Newly diagnosed & 3 & 33 & 8 \\
$<5$ & 2 & 22 & 8 \\
$5-10$ & 1 & 10 & 9 \\
$10-15$ & 7 & 16 & 30 \\
$15-20$ & 5 & 5 & 50 \\
$>20$ & 6 & 1 & 86 \\
Not known & 0 & 2 & 0 \\
\hline
\end{tabular}

(20/60)) was diabetic retinopathy; all of them had non-proliferative retinopathy.

\section{Discussion}

For screening of diabetic retinopathy, fundus photography has been recommended as a more reliable method than ophthalmoscopy. ${ }^{26}$ Some elderly people may not, however, be suitable for photographic screening owing to poor general condition or poor cooperation. In the older age groups also the quality of photographs may be compromised because of cataract. In the present study, of all inhabitants aged 70 years or older in the study area who were invited, $89 \%$ participated, and gradable fundus photographs were obtained in $74 \%$ of the eyes. ${ }^{4}$ In another $18 \%$ of the eyes information on fundus changes was obtained by ophthalmoscopy. In the diabetic population, the corresponding percentages were almost the same, $76 \%$ and $18 \%$, respectively.

The prevalence of diabetic retinopathy has been shown to increase with age, even after adjustment for duration of diabetes. ${ }^{7}$ In the Beaver Dam Eye Study the prevalence of retinopathy in elderly patients was about the same in NIDDM and in IDDM. ${ }^{8}$ Until now most population studies have excluded the oldest age groups as well as patients living in institutions. The $5 \%$ prevalence of diabetic retinopathy in the population aged 70 years or older observed in the present study corresponds closely with the prevalence figures reported in elderly people in previous studies. In the Framingham Eye Study, the prevalence of diabetic retinopathy was $4.3 \%$ in people aged 75 years and more, ${ }^{9}$ and in the most recent population based study of 6191 elderly people Stolk et $a l^{10}$ reported retinopathy in $4.8 \%$, but the age limit was 55 years or older and only non-institutionalised people were included. In a previous Finnish population sample the prevalence of retinopathy in people aged 65 years or older was only $2 \%$ of the study population. ${ }^{11}$

We observed proliferative retinopathy in only two people corresponding with the findings of Klein et al. ${ }^{12}$ This indicates that progression from background to proliferative retinopathy is less common in the elderly; neovascularisation on the disc is especially rare. In the series of Stolk et $a l^{10}$ none of the 6191 elderly subjects had proliferative diabetic retinopathy.

We found diabetic retinopathy as the main cause of low vision in 5\% of the visually handicapped in this age group. In the Finnish register of visual impairment, $8 \%$ of people aged 65 years or older registered for low vision or blindness had diabetic retinopathy as the main cause; non-proliferative diabetic retinopathy being the first diagnosis in $6.6 \%$ and proliferative retinopathy in $1.6 \% .^{13}$ In the same age group, Häkkinen ${ }^{11}$ found diabetic retinopathy as one of the causes of impaired vision (visual acuity $0.3(20 / 60)$ or less) in $6 \%$.

The low prevalence of retinopathy and particularly the low prevalence of vision threatening or treatable retinopathy decrease the cost-benefit ratio of retinopathy screening in 
this age group. In the present series any signs of retinopathy were observed in $21 \%$ of all diabetic patients, but in the majority of cases the changes were mild. Only two people ( $2 \%$ of the diabetic individuals) showed signs of proliferative retinopathy. In nine $(8 \%$ of the diabetic population) laser treatment was, however, indicated. In most cases the indication for laser treatment was decreased vision due to maculopathy. Therefore, screening for decreased visual acuity would also have discovered these cases. Considering this finding and the fact that photographs of satisfactory quality were obtained in only three quarters of the cases studied, clinical examination seems to be referrable to photography in screening for diabetic retinopathy in a population aged 70 years or older.

The study was supported financially by a grant from the Finnish Eye Foundation (Silmäsäätiö), Helsinki, Finland.

1 Klein R, Klein BEK, Moss SE. Visual impairment in diabetes. Ophthalmology 1984;91:1. 2 Fong DS, Rand LI. Epidemiology of diabetic retinopathy.
In: Albert DM, Jakobiec FA, eds. Principles and practice of In: Albert DM, Jakobiec FA, eds. Principles and practice of
ophthalmology. Basic sciences. Philadelphia: WB Saunders, ophthalmology. Bas

3 Hirvelä H, Luukinen H, Laatikainen L. Prevalence and risk factors of lens opacities in elderly people in Finland; a population based study. Ophthalmology 1995;102:108-17.

4 Laatikainen L, Hirvelä H. Prevalence and visual consequences of macular changes in a population aged 70 years or older. Acta Ophthalmol Scand 1995;73:105-10.

5 Diabetes Control and Complications Trial Research Group. The effect of intensive diabetes treatment on the progression of diabetic retinopathy in insulin-dependent diabetes mellitus. The Diabetes Control and Complications Trial. Arch Ophthalmol 1995;113:36-51.

6 Harding SP, Broadbent DM, Neoh C, White MC, Vora J. Sensitivity and specificity of photography and direct ophthalmoscopy in screening for sight threatening eye disease: the Liverpool diabetic eye study. BMF 1995;311: 1131-5.

7 Naliboff BD, Rosenthal M. Effects of age on complications in adult-onset diabetes. $\mathcal{F}$ Am Geriatr Soc 1989;37:838-42. 8 Klein R. Retinopathy in a population-based study. Trans Am Ophthalmol Soc 1992;90:561-94.

9 Kahn HA, Milton RC. Revised Framingham Eye Study prevalence of glaucoma and diabetic retinopathy. $A m \mathcal{F}$ Epidemiol 1980;111:769-76.

10 Stolk RP, Vingerling JR, de Jong PTVM, Dielemans I, Hofman A, Lamberts SWJ, et al. Retinopathy, glucose, and insulin in an elderly population. The Rotterdam Study. Diabetes 1995;44:11-5.

11 Häkkinen L. Vision in the elderly and its use in social environment. Scand F Soc Med 1984:35 (Suppl).

12 Klein R, Klein BEK, Moss SE. Epidemiology of proliferative diabetic retinopathy. Diabetes Care 1992;15:1875-91.

13 National Research and Development Centre for Welfare and Health in Finland. The Finnish Register of Visual Impairment. Helsinki: 1993 Annual Statistics, 1994. 